\title{
Study of the cycle variability at an automotive diesel engine fuelled with LPG
}

\author{
Liviu Nemoianu ${ }^{1}$, Constantin Pana $^{1}$, Niculae Negurescu ${ }^{1}$, Alexandru Cernat ${ }^{1}{ }^{1}$, Dinu \\ Fuiorescu ${ }^{1}$, and Cristian Nutu $^{2}$ \\ ${ }^{1}$ University Politehnica of Bucharest, Department of Thermotechnics, Engines, Thermical and \\ Frigorific Equipment, Splaiul Independentei 313, Bucharest, Romania \\ ${ }^{2}$ University Politehnica of Bucharest, Department of Automotive Engineering, Splaiul Independentei \\ 313, Bucharest, Romania
}

\begin{abstract}
Liquid Petroleum Gas is a viable alternative fuel for diesel engines due to its ability of emissions and fuel consumption reduction. Combustion variability at LPG diesel engine is analysed for maximum pressure, maximum pressure angle and indicated mean effective pressure. Combustion variability is influenced by the increase of LPG cycle dose which lead to the increase of the cycle variability coefficients values, but without exceeding the admitted values that provide diesel engine reliability. Analysis of COV values establishes the maximum admitted values of LPG cycle.
\end{abstract}

\section{Introduction}

Nowadays, in the global content regarding the impact on the environmental of the gas emissions resulted from the fossil fuels combustion, including the impact of diesel engine on environment, special measures are taken in order to reduce as much as possible the pollution especially in the urban areas. This issue was discussed at the 21 st Session of the Conference of the Parties (COP21) from the 2015 Paris Climate Conference. Moreover, since the C40 Events-C40 Mayors Summit 2016 (in December 2016) pollution issue becomes a priority for some capital cities (like Paris, Madrid, Athens and Mexico City) which want to be free from automotive diesel engines by 2020 and for the whole France by 2025. The progressive diminution of the oil reserves all over the world highlights the necessity of using alternative energy derived from durable and renewable resources, [1]. The use of the alternative fuels, even in partial substitution, may represent a viable solution to reduce the pollutant emissions, but it's important to maintain the normal engine manoeuvrability for the new fuelling solution, [1]. The Liquid Petroleum Gas (LPG), an alternative fuel used on large scale at spark ignition engines, offers the advantage of an already existing distribution infrastructure in many European countries, [1]. The LPG can be use as alternative fuel at diesel engines with remarkable reductions of soot and $\mathrm{NO}_{\mathrm{X}}$ emissions, [1]. Ying Wang [2] studied the combustion in a diesel dual-fuel premixed charge compression ignition combustion engine with LPG as ignition inhibitor showing the

\footnotetext{
*Corresponding author: cernatt@gmail.com, cernatalex@yahoo.com
} 
influence on the appearing positions of the maximum cylinder pressure and on pressure peak values when LPG mass fraction in DME (dimethyl ether)/LPG mixture increases. At the same time the $\mathrm{NO}_{\mathrm{X}}$ emission decrease slightly, [2]. Surawski [3] shows that the use of LPG leads to the pre-mixed combustion of LPG-air mixture followed by the in-cylinder maximum pressure and pressure rise rate increase. Polk [4] limits to maximum the propane substitutions so the $\mathrm{NO}_{\mathrm{X}}$ and smoke emissions decrease. Boretti [5] converts a heavy duty truck diesel engine to operate with diesel fuel-LPG, showing the reduction of particulate and $\mathrm{CO}_{2}$ emissions. Tira [6] uses the LPG (100\% propane) for diesel engine fuelling and calculate the coefficient of variability (COV) of Indicated Mean Effective Pressure (IMEP) to evaluate the combustion stability from a minimum of 200 cycles. Tira observes an accelerated combustion of the mixture and an increased in-cylinder pressure [6]. At low load the LPG addition causes a reduced combustion duration, being established the maximum fraction of LPG addition with acceptable cycle combustion variability, COV $_{\text {IMEP }}$ $<5 \%$, [6]. Elnajjar [7] uses a single cylinder, naturally aspirated, four strokes with indirect injection, water cooled Ricardo E6 diesel engine. Different composition of LPG has lower impact on the engine efficiency and has a significant influence on the combustion noise level [7]. Tira [8] analyses the running of a LPG-diesel dual fuelled engine operated with rapeseed methyl ester and gas-to-liquid diesel fuels, proofing that the combustion cycle variability remains acceptable in running conditions at which $60 \%$ of liquid fuel was substituted by LPG. Selim [9] presents the performance of dual fuel engine running on natural gas/LPG by using pilot fuel derived from jojoba seeds. Selim uses 100 cycles for cyclic variability evaluation and determinates the combustion noise defined by the incylinder maximum pressure and maximum pressure rise rate, [9]. The use of jojoba fuel and LPG leads to diesel engine performance increases, the combustion noise and the cyclic variability of the combustion being reduced, [9]. Ashok [10] shows the performance, combustion and emission characteristics of the LPG diesel dual fuel engine by using intake gaseous fuel. The use of LPG fuel at a high compression ratio engine leads to the increase of combustion noise and of the cyclic variation of the combustion, [10]. Renald [11] shows that at the fuelling with $60 \%$ of diesel and $40 \%$ of LPG the thermal efficiency of the diesel engine increases with about $5 \%$ when and the mechanical efficiency was increased about $5 \%$. Poonia [12] use a single cylinder diesel engine fuelled with LPG at the load regime of $3.7 \mathrm{~kW}$ at speed of $1500 \mathrm{~min}^{-1}$, recording 100 in-cylinder pressure diagrams for cyclic variation evaluation. At diesel fuelling the COV of IMEP is below $6 \%$ and the COV of maximum pressure is under $2 \%$ comparative to dual fuelling. Once with the rise of engine load, up till $80 \%$, the COV values rise too for diesel-LPG fuelling [12]. For all engine loads, the COV of peak pressure is higher than diesel mode and is influenced by the irregular combustion process of air-LPG mixture, [12]. For engine loads bigger than $60 \%$ and exhaust gas recirculation (EGR) use raised values of COV are registered because the combustion velocity is reduced by the EGR [12].

In this paper the combustion cycle variability of a K9K diesel engine (from Dacia Logan MCV van) fuelled with LPG by diesel gas method is analyzed. At LPG fuelling important reductions of soot (with 60\%), $\mathrm{NO}_{\mathrm{X}}$ (with 40\%) and $\mathrm{HC}$ (with $80 \%$ ) emissions were obtained, [1]. The LPG injectors are connected to the inlet manifold and electronic controlled by a special ECU connected back to back with the main engine ECU (Engine Control Unit).

\section{Methodology of the experimental research}

The LPG cycle quantity is evaluated by an energetic substitute ratio $\mathrm{x}_{\mathrm{c}}$ taking into consideration the lower heating values of LPG and diesel fuel. The value of $x_{c}=0$ [\%] is set up as reference regime (engine fuelled with only diesel fuel). The coefficients of cycle 
variability $(\mathrm{COV})$ used to evaluate the intensity of cycle-to-cycle variation are calculated with the relation (1):

$$
(\operatorname{COV}) \mathrm{a}_{\mathrm{i}}=\frac{\sqrt{\frac{\sum_{\mathrm{i}=1}^{\mathrm{n}}\left(\mathrm{a}_{\mathrm{i}}-\frac{\sum_{\mathrm{i}=1}^{\mathrm{n}} \mathrm{a}_{\mathrm{i}}}{\mathrm{n}}\right)^{2}}{\mathrm{n}-1}}}{\frac{\sum_{\mathrm{i}=1}^{\mathrm{n}} \mathrm{a}_{\mathrm{i}}}{\mathrm{n}}} \cdot 100 \%
$$

where $n$ is the number of cycles, $a$ is the parameter of which variability is study and is defined by indicated mean effective pressure IMEP, maximum pressure $\mathrm{p}_{\max }$ and the angle where maximum pressure occurs, $\alpha_{\text {pmax }}$ in the cycle number " $i$ ", $[1,13]$. The COV of maximum pressure is suitable at cycle-by-cycle variability evaluation for regimes with injection timing closer to the value of timing for MBT (Maximum Brake Torque). The COV of maximum pressure angle, $\alpha_{\text {pmax }}$, reflects the combustion variability during the first phase of combustion. The (COV) IMEP shows how the engine responds to the combustion variability $[1,13]$. The accepted limit value of $(\mathrm{COV})_{\text {IMEP }}$ defines the limit of in-cylinder mixture leaning and reflects the variability of flame development during the first phase of combustion. The COV values for maximum pressure and IMEP are taking into consideration when the limit value of $x_{c}$ is established. If $(\mathrm{COV})_{\text {pmax }}$ and $(\mathrm{COV})_{\text {IMEP }}$ don't exceeded $10 \%$ the normal automotive manoeuvrability is assured $[1,13]$. Thus, the cycle variability study has a significant relevance when alternative fuels, like LPG, are used to diesel engine in order to evaluate the response of the engine to the variability of the LPG combustion. To establish if the LPG is a suitable alternative fuel for diesel engines and can assure the normal mechanical operation of the engine and good drive ability, not only the pollutant emissions decreasing, such a study is mandatory.

\section{Results}

The regime of $2000 \mathrm{~min}^{-1}$ and $85 \%$ load, a regime of full load and maximum torque brake, offend used in the operation of the commercial vehicles, was investigated at dual fuelling. For a correct cycle variability study, a number of 150 consecutive pressure diagrams have being measured and registered by AVL Indimodul 621 data acquisition system and analyzed in terms of maximum pressure, maximum pressure angle, IMEP and angles of 5\% mass fraction burned (MFB) for different substitute ratios, $\mathrm{x}_{\mathrm{c}}$. The cycle dispersion registered between values of maximum pressure, in consecutive cycles, is shown in the Figure 1. Next to the values find it in the average cycles, the minimum and maximum values registered in the individual cycles are shown. The COV values for maximum pressure are: 0.56 at $\mathrm{x}_{\mathrm{c}}=0 ; 0.57$ at $\mathrm{x}_{\mathrm{c}}=2.5 ; 0.65$ at $\mathrm{x}_{\mathrm{c}}=6.7$ and 1.44 for $\mathrm{x}_{\mathrm{c}}=28$. The coefficient $(\mathrm{COV})_{\text {pmax }}$ don't exceed values of $1.44 \%$, but the increase tendency of $(\mathrm{COV})_{\text {pmax }}$ with the rise of $x_{c}$ values can be take into consideration, especially for $x_{c}=28 \%$. The value registered for $\mathrm{x}_{\mathrm{c}}=28 \%$ is 2.5 times bigger comparative to the value of standard engine. The increase of LPG cycle dose leads to the increase of maximum pressure, maximum pressure cycle dispersion and of the dispersion of successive running cycles. The angle of maximum pressure, $\alpha_{\text {pmax }}$, is registered closer to the TDC, with is related to a rapid, brutal combustion, Figure 2. 


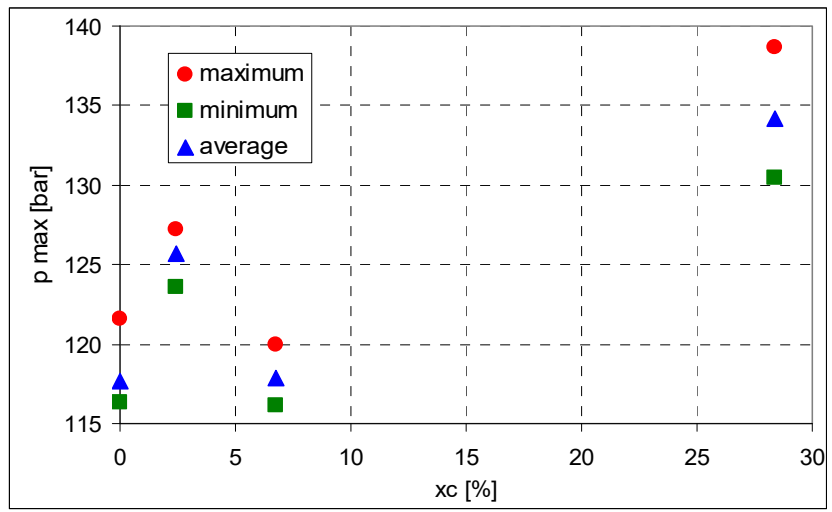

Fig. 1. Cyclic dispersion of maximum pressure values versus $x_{c}$ at $2000 \mathrm{~min}^{-1}$ speed and $85 \%$ load.

The COV values for angle of maximum pressure are: 12.5 at $\mathrm{x}_{\mathrm{c}}=0 ; 9.7$ at $\mathrm{x}_{\mathrm{c}}=2.5 ; 12.4$ at $\mathrm{x}_{\mathrm{c}}=6.7$ and 12.7 for $\mathrm{x}_{\mathrm{c}}=28$.

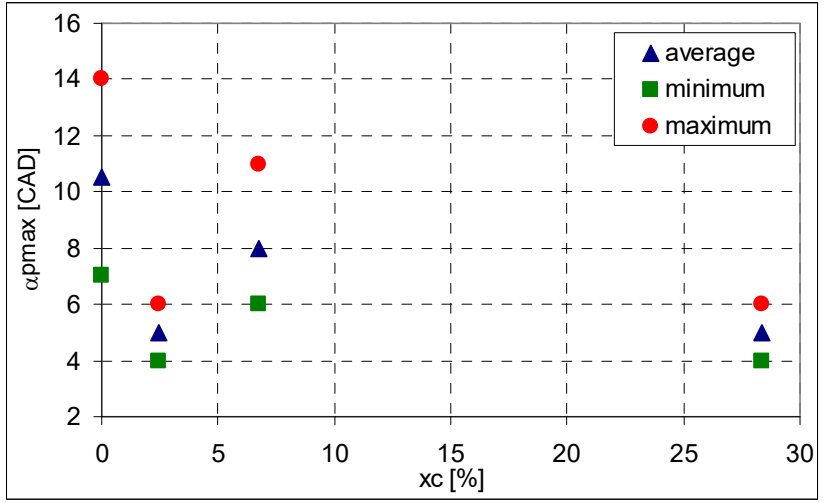

Fig. 2. Cyclic dispersion of angles of maximum pressure versus $x_{c}$ at $2000 \mathrm{~min}^{-1}$ speed and $85 \%$ load.

The variability of maximum pressure angle slightly decreases comparative to reference regime for the maximum $\mathrm{x}_{\mathrm{c}}$, but for averaged $\mathrm{x}_{\mathrm{c}}$ values the dispersion is similar to diesel fuelling. For $\mathrm{x}_{\mathrm{c}}=2.5 \%$ the $(\mathrm{COV}) \alpha_{\mathrm{pmax}}$ is improved comparative to diesel fuelling. The increasing tendency of $(\mathrm{COV}) \alpha_{\mathrm{pmax}}$ for some $\mathrm{x}_{\mathrm{c}}$ can be related with the increased cycle variability during the initial phase of combustion, COV of $\alpha 5 \%$, Figure 4 . The COV values for IMEP are: 1.1 at $\mathrm{x}_{\mathrm{c}}=0 ; 1.57$ at $\mathrm{x}_{\mathrm{c}}=2.5 ; 0.7$ at $\mathrm{x}_{\mathrm{c}}=6.7$ and 1.3 for $\mathrm{x}_{\mathrm{c}}=28$. The limitation of $(\mathrm{COV})_{\text {IMEP }}$ leads to the reduction of the variability of flame development during the premixed stage of combustion. Variability of the flame development during combustion premixed phase may be affected by the increase of $x_{c}$. For $x_{c}=28 \%(C O V)_{\text {IMEP }}$ is 1,4 times bigger comparative to reference value, the limitation of $x_{c}$ to $28 \%$ can maintain the normal engine running at this regime. If the admitted limit is $\left[(\mathrm{COV})_{\mathrm{IMEP}}\right]_{\max }=10 \%$, then appears no limitation issue at $\mathrm{x}_{\mathrm{c}}=28 \%$ for this operating regime. If the substitute ratio is limited to $\mathrm{x}_{\mathrm{c}}=28 \%$ the maximum pressure and maximum pressure rise rate are limited at $\mathrm{p}_{\max }=138$ bar and $(\mathrm{dp} / \mathrm{d} \alpha)_{\max }=6.68 \mathrm{bar} / \mathrm{CAD}$, respectively, values measured in individual cycles. This phenomenon is related with a combustion process closer to TDC (Top Dead Centre) and leads to the increasing of the maximum pressure rise rate during the combustion process. 


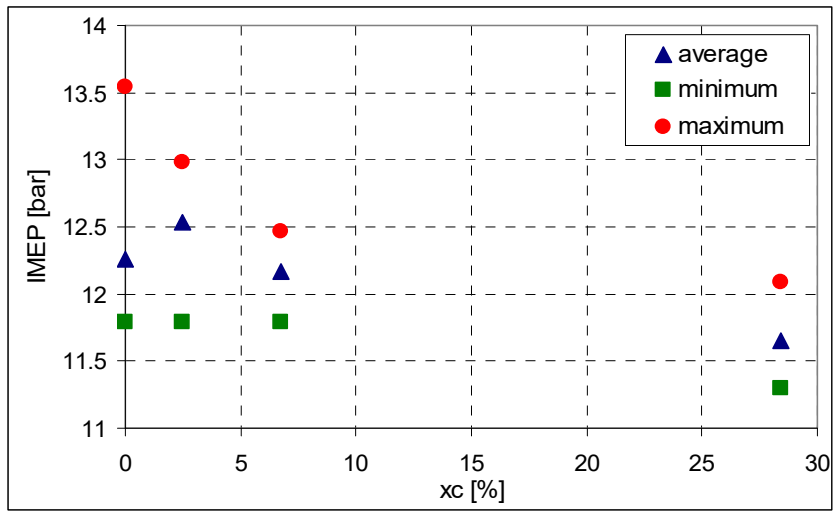

Fig. 3. Cyclic dispersion of IMEP values versus $x_{c}$ at $2000 \mathrm{~min}^{-1}$ speed and $85 \%$ load.

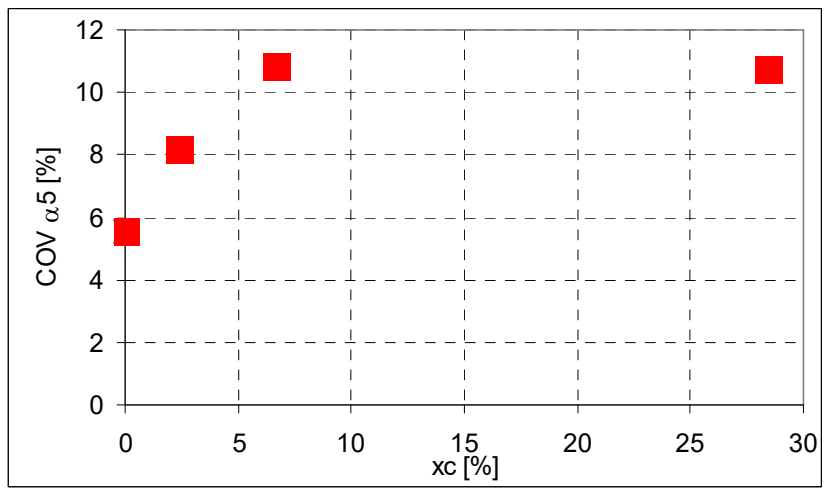

Fig. 4. Coefficient $(\mathrm{COV})_{\alpha 5}$ of MFB versus $\mathrm{x}_{\mathrm{c}}$ at $2000 \mathrm{~min}^{-1}$ speed and $85 \%$ load.

The initial very lean mixtures of air-LPG achieved in-cylinder before combustion starts will influence the engine mechanical running and the cycle variability at the beginning of the combustion process, evaluated by variability of the angle of $5 \%$ of mass fraction burned. The $\mathrm{COV} \alpha_{5} \%$ increases from 5.6, for diesel fuelling to 10.7 at maximum LPG dose, Figure 4. This increase is in correlation with the raised cycle variability of maximum pressure and of IMEP and in order to assure the normal manoeuvrability of the engine at LPG fuelling the $\mathrm{x}_{\mathrm{c}}$ value must be limited at $28 \%$ for the investigated regime.

\section{Conclusions}

The experimental study of dual fuelled diesel engine leads to the following conclusions: The diesel and LPG engine fuelling leads to the increase of in-cylinder maximum pressure and of its cycle variability coefficient $(\mathrm{COV})_{\text {pmax }}$. The increased values of $(\mathrm{COV})_{\text {pmax }}$ at $\mathrm{x}_{\mathrm{c}}=6.7 \ldots 28 \%$ are related with the increased dispersion between the angles of maximum pressure and upper values of $(\mathrm{COV}) \alpha_{\text {pmax }}$. This aspect may reflect the increase of the combustion cycle variability during the premixed combustion phase at the increase of $\mathrm{x}_{\mathrm{c}}$ over $28 \%$. The LPG fuelling leads to the increase of maximum pressure rise rate $(\mathrm{dp} / \mathrm{d} \alpha)_{\max }$ and of the cycle variability, evaluated by $(\mathrm{COV})_{\text {IMEP. In order to assure a good drive ability }}$ of the dual fuelled diesel engine the LPG dose, $x_{c}$, is limited by the maximum values or by the maximum variation interval of same running characteristic parameters of the engine, as 
is follows: if the maximum admissible level of the cycle variability is $(\mathrm{COV})_{\mathrm{IMEP}}=1.3 \%$, then the substitute ratio will be limited to $\mathrm{x}_{\mathrm{c}}=28 \%$; if the maximum pressure rise rate is limited to the value $(\mathrm{dp} / \mathrm{d} \alpha)_{\max }=6.68 \mathrm{bar} / \mathrm{CAD}$, then the LPG substitute ratio will be limited at $\mathrm{x}_{\mathrm{c}}=28 \%$, value that will leads to a maximum acceptable in-cylinder pressure level of 138 bar that assure the normal engine operation. LPG fuelling leads to the increase of the cycle variability of the beginning of combustion process, with the rise of $(\mathrm{COV}) \alpha_{5 \%}$, fact that influence the cycle variability of IMEP, $(\mathrm{COV})_{\text {IMEP }}$. The cycle variability study shows that the influence of LPG fuelling on combustion process and on engine mechanical operation are minimal if the limited $x_{c}$ values are respected. Thus, the study relives that the LPG is a viable alternative fuel for diesel engines and the benefits of pollutant emissions decreasing can be also assured for a normal engine running. The values of the calculated COV parameters show a good manoeuvrability of the LPG fuelled diesel engine and define the LPG as a viable alternative fuel for diesel engines.

Partial, the work has been funded by the Sectoral Operational Programme Human Resources Development 2007-2013 of the Ministry of European Funds through the Financial Agreement POSDRU/159/1.5/S/134398. This work has been founded by University Politehnica of Bucharest through the "Excellence Research Grants" Program, UPB-GEX. Identifier: UPB-EXCELENTA-2016 Experimental Researches of hydrogen use at diesel engine. Contract number 38/26.09.2016. The authors address special thanks to AVL GmbH Graz Austria for providing the necessary equipments.

\section{References}

1. C. Pana, N. Negurescu, M. G. Popa, A. Cernat, UPB Sci. Bull., Series D, 72 (1) (2010)

2. Y. Wang, H. Liu, Z. Huang, et al., Energy 96, 278-285 (2016)

3. N.C. Surawski, B. Miljevic, et al., Fuel 133, 17-25 (2014)

4. A. C. Polk, C. D. Carpenter, K. K. Srinivasan, et al., Fuel 132, 135-148 (2014)

5. A. Boretti, F.P.T. 113, 97-108 (2013)

6. H. S. Tira, J. M. Herreros, et al., Fuel 118, 73-82 (2014)

7. E. Elnajjar, M. O. Hamdan, et al., Renew. Energy 56, 110-116 (2013)

8. H.S. Tira, J.M. Herreros, et. al., Energy 47 (1), 620-629 (2011)

9. M. Selim, et. al., Renew. Energy 33, 1173-1185 (2008)

10. B. Ashok, S. Denis, C. Ramesh, C., Kumar, Alexandria Engineering Journal 54, 105$126(2015)$

11. R. Thomas, P. Somasundaram, Energy Procedia 14, 1427 - 1438 (2012)

12. M.P. Poonia, Y. B. Mathur, J.E.R.D. 7 (2), 746-755 (2012)

13. J. B. Heywood, Internal Combustion Engines Fundamentals (McGraw-Hill Book Company, 1988) 